\title{
E6/E7 mRNA expression analysis: A test for the objective assessment of cervical adenocarcinoma in clinical prognostic procedure
}

\author{
SIRI HOVLAND ${ }^{1}$, SUSANNE MULLER ${ }^{2}$, HANNE SKOMEDAL $^{1}$, MICHAEL MINTS $^{3}$, JAKOB BERGSTRÖM ${ }^{4}$, \\ KENG-LING WALLIN ${ }^{5}$, FRANK KARLSEN ${ }^{1}$, BO JOHANSSON ${ }^{6}$ and SONIA ANDERSSON $^{2}$ \\ ${ }^{1}$ NorChip AS, Klokkarstua, Norway; ${ }^{2}$ Department of Clinical Science, Intervention and Technology, \\ Division of Obstetrics and Gynecology, Karolinska University Hospital, Huddinge, Karolinska Institutet, \\ SE-141 86 Stockholm; ${ }^{3}$ Karolinska Biomics Center, Department of Oncology and Pathology, Karolinska Institutet, \\ Karolinska University Hospital, SE-171 76 Stockholm; ${ }^{4}$ Medical Statistics Unit (MedStat) Department of Learning, \\ Informatics, Management and Ethics (LIME), Karolinska Institutet, SE-171 77 Stockholm; ${ }^{5}$ Department of Molecular \\ Medicine and Surgery, Karolinska University Hospital-Solna, Karolinska Institutet, SE-171 76 Stockholm; \\ ${ }^{6}$ Division of Clinical Virology, Department of Laboratory Medicine, Karolinska University \\ Hospital at Huddinge, Karolinska Institute, SE-141 86 Stockholm, Sweden
}

Received December 30, 2009; Accepted February 18, 2010

DOI: 10.3892/ijo_00000640

\begin{abstract}
Detection of E6/E7 mRNA expression using the real-time nucleic acid sequence-based amplification assay (NASBA) PreTect HPV-Proofer was compared with results of human papillomavirus (HPV) DNA detection in 98 paraffin-embedded samples from patients with cervical adenocarcinoma. HR-HPV DNA was detected in $61(62 \%)$, while HR-HPV E6/E7 mRNA was detected in $63(64 \%)$ of the samples. Correlation between results from DNA analyses and the E6/E7 mRNA assay showed consistent results in $87 \%$ of samples (47 of 54). The results from these two methods in detecting presence of HPV infection of any type agreed in $77 \%$. Overall agreement between the methods was seen in 82 of the 98 cases (84\%). When evaluating change in sensitivity for detection of HPV positives by adding more HPV types to the HPV DNA assay, maximum sensitivity was reached by targeting four HPV types. The coverage of HPV DNA presence was $76.9 \%$, while the E6/E7 mRNA assay achieved a maximum coverage of $80.8 \%$ using only three HPV types. Thus, E6/E7 oncogene expression analysis may provide a more objective test for assessment of neoplastic glandular cells. Further studies may reveal whether the
\end{abstract}

Correspondence to: Dr Sonia Andersson, Department for Clinical Science, Intervention and Technology, Division of Obstetrics and Gynecology, Karolinska University Hospital, Huddinge, Karolinska Institutet, 14186 Stockholm, Sweden

E-mail: sonia.andersson@karolinska.se

Key words: adenocarcinoma, paraffin, mRNA, DNA, nucleic acid sequence-based amplification, cervix, human papillomavirus clinical performance of the E6/E7 mRNA assay will be of prognostic value in management of cervical adenocarcinoma.

\section{Introduction}

Cervical cancer remains the second most common form of cancer among women worldwide, with an estimated half a million new cases and a quarter of a million deaths each year (1). In Sweden $\sim 450$ women are diagnosed with invasive cervical cancer, and 150 die each year from the disease (2).

In the last decade, however, an increase in the incidence of invasive adenocarcinoma (AC), which comprises 10-20\% of all cervical cancers, has been observed in several countries, where functional cervical screening programs exist $(3,4)$.

Through cytological screening, precursor lesions can be detected and removed before cancer develops. Due to its location high up in the endocervical canal, AC and its precursor lesions, adenocarcinoma in situ (AIS), are generally considered more difficult to detect through routine Pap smear screening (5).

The predominant etiologic agent in cervical cancer is infection with high risk human papillomavirus (HR-HPV), found to be present in $>95 \%$ of squamous cell carcinoma (SCC) and in between 55 and $90 \%$ of AC (6).

About $80 \%$ of infections with HR-HPV are transient, probably because of a T-cell response to HPV (7). Approximately $1 \%$ of women infected with HR-HPV will eventually develop cervical cancer (8). HPV types 16 and 18 are the most common in invasive cervical cancers, with type 18 being significantly more common in cervical AC than in SCC (9).

In a small subset of women, persistent HR-HPV infection will lead to transformation through integration of portions of the HPV genome into the host cell genome. Expression of the E6 and E7 viral oncogenes is maintained, while expression of 
other viral genes is disturbed or disrupted. Disruption of the E2 gene, which may result in deregulated E6/E7 expression through transcriptional derepression, is important since it allows E6/E7 expression to continue while other genes are suppressed. HR-HPV E6/E7 expression in turn augments genomic instability through induction of centrosome abnormalities. HR-HPV E6/E7 proteins inactivate growth inhibitors within the cell, most importantly the tumor suppressors, pRB and p53 (10). HPV-related malignant growth requires the presence of full-length E6/E7 oncoproteins $(11,12)$.

Compared with cytological screening, HPV DNA-based testing has demonstrated higher sensitivity for histologicallyverified cervical neoplasia. Due to the high prevalence of transient infections, most HPV DNA-positive cases never develop any kind of dysplasia $(13,14)$. In addition, it has been far more difficult to establish a causal link between HPV DNA and adenocarcinoma than it is for HPV DNA and squamous cell cancer, since a significant number of adenocarcinoma cases exhibit no HR-HPV presence (6).

Since expression of E6/E7 oncogenes is necessary for development of cervical intraepithelial neoplasia and subsequent cervical cancer, testing for HR-HPV E6/E7 mRNA as a sign of persistent expression of E6/E7 oncogenes of infected cells could provide a more effective means for early detection of cervical cancer, especially AdCx (15).

The aim of this study was to evaluate whether the realtime NASBA-based PreTect HPV-Proofer assay (NorChip AS, Klokkarstua, Norway) can be used to detect the full-length mRNA E6/E7-region of five HR-HPV types in paraffinembedded tissue samples of cervical adenocarcinoma. We also wanted to analyze whether the PreTect HPV-Proofer is a more sensitive method for detection of adenocarcinoma of the cervix due to transforming HPV infection, than the DNA test in paraffin-embedded material. For this purpose we examined HPV status in a series of cervical adenocarcinomas using the PreTect HPV-Proofer and compared it with typing by SSCP or direct DNA sequence analysis after PCR amplification as well as by the Linear Array HPV genotyping test in a subset of these cases.

\section{Patients and methods}

Tumor material. The study includes formaldehyde-fixed paraffin-embedded tumor tissue specimens from 98 primary cervical adenocarcinomas diagnosed and surgically treated at Karolinska University Hospital-Huddinge between 1992 and 2000. Clinical information from these cases has in part been previously published (16).

According to histopathology, eight adenocarcinomas showed only superficial proliferation of the mucosa and no obvious signs of infiltration into the surrounding stroma were present. These tumors were regarded as 'in situ adenocarcinomas', while the remaining 90 tumors were considered to be 'infiltrating cervical adenocarcinomas'. All patients were retrospectively followed-up from time of diagnosis until January 2007 and disease recurrence and survival data were recorded.

Extractions from all blocks (total of 98) were carried out twice. The first round of extractions was used for GP5/6+ PCR followed by SSCP-typing, or PCR for direct DNA sequencing. The second round of extractions was for mRNA analyses. A third round of extractions was carried out exclusively on cases testing negative (N28) to allow an opportunity to perform the Linear Array HPV genotyping test (LA).

HPV DNA analyses by $G P 5^{+} / 6^{+} P C R$. The flow chart in Fig. 1 summarizes the study design. Results from HPV analyses have previously been published for all cases (17).

HPV DNA typing. HPV was typed using direct nonradioisotopic single-strand conformational polymorphism (SSCP) (18) and/or by direct DNA sequencing of a PCR-amplified L1 target (6).

Samples showing inconsistent results were further analyzed by reverse line blot (RLB) hybridization, provided sufficient material was available. RLB hybridization was performed using a previously described assay (19).

HPV RNA analysis by NASBA. Paraffin-embedded tissue blocks were sliced with a microtome blade into five $10-\mu \mathrm{m}$ sections and transferred to $1.5 \mathrm{ml}$ RNase-free vials and stored at $4^{\circ} \mathrm{C}$. The microtome and forceps were cleaned with $70 \%$ ethanol twice between each sampling to prevent contamination between blocks. Sections for DNA and RNA analysis were incubated in two consecutive baths of xylene for $10 \mathrm{~min}$ each before centrifugation for $5 \mathrm{~min}$ at $2500 \mathrm{rpm}$, followed by two consecutive baths in $100 \%$ ethanol, 10 min each. After final centrifugation for $5 \mathrm{~min}$ at $2500 \mathrm{rpm}$, the pellets were dried at $55^{\circ} \mathrm{C}$ for $2-4 \mathrm{~h}$ and treated for at least $3 \mathrm{~h}$ with $100 \mu 10.5 \mathrm{mg} /$ $\mathrm{ml}$ proteinase K (Invitrogen, Carlsbad, USA, $20 \mathrm{mg} / \mathrm{ml}$ ) in RNase-free $1 \mathrm{X}$ Tris-HCl (Sigma Aldrich, St. Louis, USA) at $55^{\circ} \mathrm{C}$ until digestion was complete. Finally, $900 \mu 1$ lysis buffer (Nuclisens, bioMérieux, Marcy l'Etoile, France) was added to each tube before extraction using the NucliSens manual extraction kit (bioMérieux). Extracts were stored at $-80^{\circ} \mathrm{C}$.

Full-length mRNA from HPV types 16, 18, 31, 33, and 45 were detected using the real-time NASBA-based assay (PreTect HPV-Proofer, NorChip AS), according to the manufacturer's instructions.

To avoid false negatives due to degradation of mRNA, primers and probes against human U1A mRNA are included in the HPV-Proofer kit for performance and integrity control. However, the U1A control was found to be suboptimal for integrity control in paraffin-embedded tissue due to modified or fragmented nucleic acids, and was therefore replaced by glyceraldehyde-3-phosphate dehydrogenase (GAPDH). The amplicon defined by the GAPDH primers was adjusted in size to better match the HPV amplicons. Thus, GAPDH primers achieved approximately the same sensitivity as the HPV primers (unpublished data).

The cases that were still HPV-negative for both mRNA and DNA after examination with $\mathrm{GP}^{+} / 6^{+} \mathrm{PCR}$ followed by typing and PreTect HPV-Proofer were further analyzed using the Linear Array (LA) HPV genotyping test (Roche Diagnostics, Basel, Switzerland).

HPV DNA extraction and detection with Linear Array. Paraffin-embedded archival biopsies were de-waxed with xylene-ethanol and DNA was extracted using a MagNA Pure 


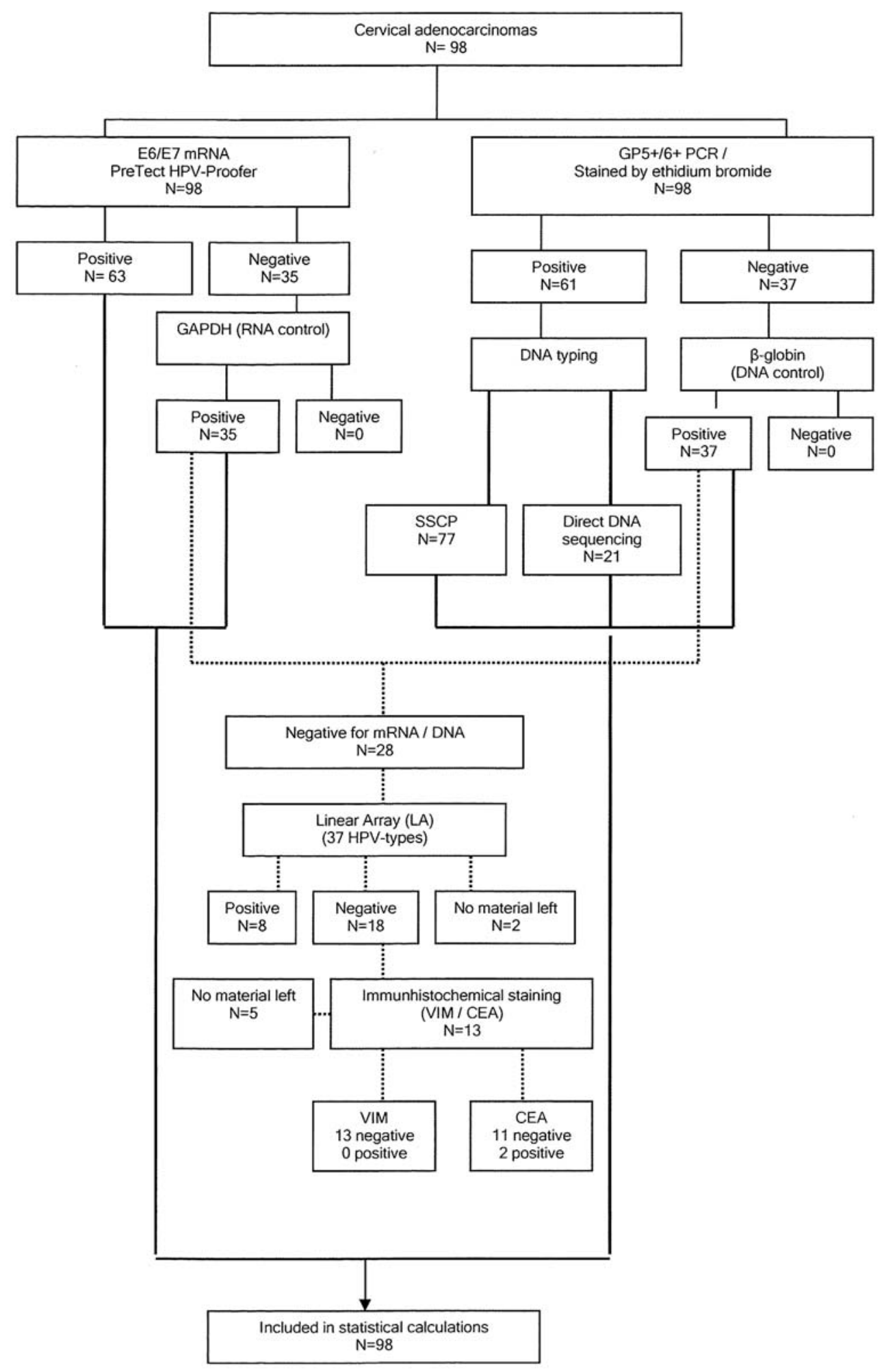

Figure 1. Flow chart illustrating the design of the study.

LC Robot in accordance with the procedure outlined in the manufacturer's manual (Roche Diagnostics). HPV-DNA detection and genotyping were carried out using the Linear Array (LA) HPV genotyping test outlined in the manufacturer's manual (Roche Diagnostics), which includes $37 \mathrm{HPV}$ types divided into three 'risk categories' according to Muñoz and co-workers (20).

Furthermore, the HPV mRNA and DNA negative tumors were histopathologically re-evaluated and revealed typical morphology of cervical adenocarcinoma, consistent with the initial diagnosis. A total of 13 cases remained HPV negative after testing by both DNA methods, including Linear Array (seven of the initial 28 cases had no material left), as well as the mRNA methods, and were therefore further examined by immunohistochemical staining for vimentin (VIM) and monoclonal carcinoembryonic antigen (CEA) to exclude potential cases originally arising from endometrial tissue. Results are summarized in Fig. 1. Samples were diagnosed in 
Table I. Mismatches between HPV types detected by mRNA vs. DNA tests.

\begin{tabular}{|c|c|c|}
\hline \multirow{2}{*}{$\frac{\text { mRNA method }}{\text { PreTect HPV-Proofer }}$} & \multicolumn{2}{|c|}{ DNA method } \\
\hline & SSCP & RLB \\
\hline HPV 18 & HPV 45 & NT \\
\hline HPV 16 & HPV 18 & HPV 16 \\
\hline HPV 16/31 & HPV 16 & NT \\
\hline HPV 45 & HPV 18 & HPV 45 \\
\hline HPV 45 & HPV 18 & NT \\
\hline HPV 16 & HPV X & HPV 16 \\
\hline HPV 45 & HPV 18 & HPV 45 \\
\hline HPV 45 & HPV 31/33 & NT \\
\hline
\end{tabular}

NT, not tested with RLB due to insufficient sample material.

a blinded fashion, i.e., the respective assessment was disclosed only after both the HPV DNA and HPV mRNA and histology had been evaluated.

Statistical analysis. Age stratified ( $<70$ years and $\geq 70$ years) Cox regression analysis was performed to evaluate the difference in survival between HPV mRNA-positive and HPVnegative cases. The analysis was performed using SPSS 17.0. $\mathrm{P}<0.05$ was considered significant. Various measures of diagnostic accuracy were used to assess the detection rate of HPV positives for different combinations of HPV types.

\section{Results}

See Fig. 1 for an overview and results from the analyses. Mismatches between DNA and mRNA were observed in eight cases (all initially analyzed by PCR-SSCP) and four of these cases were reanalyzed by RLB for comparison (Table I). In these cases the results of mRNA typing were confirmed. The remaining four could not be tested due to lack of sample material.

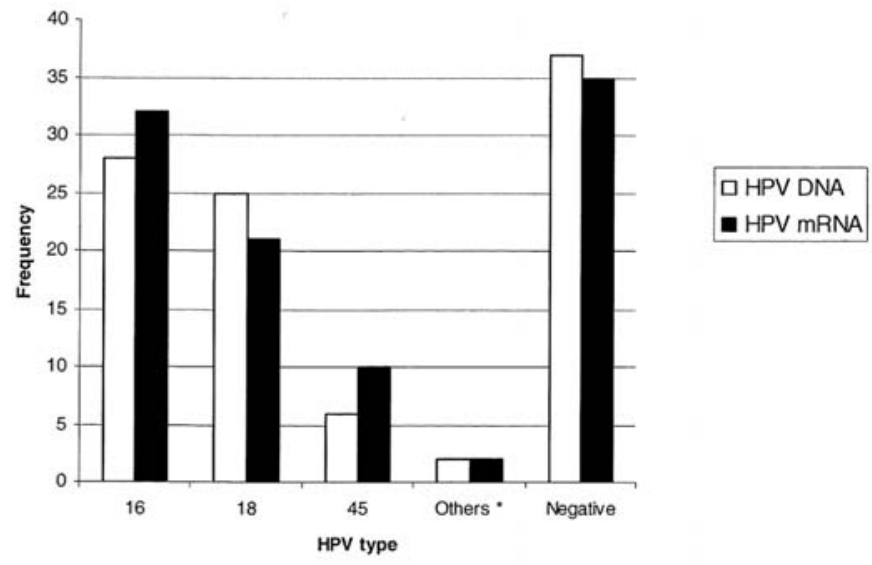

Figure 2. Detection of different HPV types with DNA (white bars) and mRNA (black bars) methods. The asterick includes HPV DNA 31/33 and an unknown case; HPV mRNA 16/18 and HPV16/31.

Frequencies of HR-HPV DNA and E6/E7 mRNA. Of the 98 samples analyzed by SSCP or direct DNA sequencing, HRHPV was detected in $61(62 \%)$ of the samples, whereas HRHPV E6/E7 mRNA was detected in 63 (64\%) of the samples. All extracts from paraffin-embedded tissue samples were positive for the GAPDH mRNA integrity control and/or were positive for HPV and could therefore be included in the highrisk HPV E6/E7 mRNA analysis.

Of the 28 cases that remained HPV-negative after evaluation with $\mathrm{GP}^{+} / \mathrm{GP}^{+} \mathrm{PCR}$ and PreTect HPV-Proofer, eight additional cases were HPV-positive using LA (seven cases for HPV 16, one case for HPV 52); eighteen remained negative, while two had no material left for LA analysis.

The frequencies of the different HR-HPV types found with PreTect HPV-Proofer and SSCP/direct DNA sequencing in samples from cervical adenocarcinoma are summarized in Fig. 2. Analysis of the results from DNA testing and E6/E7 mRNA assay showed consistent results in $87 \%$ of the samples. The methods showed agreement in 54 cases $(77 \%)$ for presence of HPV infection of any type. Nine $(9 \%)$ of the samples showed infection with HPV in the mRNA assay alone, and 7 (7\%) tested positive for HPV only by consensus PCR.

Table II. Number of TP, FN, TN detected in HPV positives (by any method) in cervical adenocarcinoma using SSCP and direct sequencing.

\begin{tabular}{|c|c|c|c|c|c|c|}
\hline HPV type in cocktail & \# Types & \# TP & \# FN & $\# \mathrm{FP}^{\mathrm{b}}$ & $\# \mathrm{TN}$ & Sensitivity \\
\hline 0 & 0 & 0 & $78^{\mathrm{a}}$ & 0 & 20 & $0.0 \%$ \\
\hline HPV 16 & 1 & 28 & 50 & 0 & 20 & $35.9 \%$ \\
\hline HPV 16-18 & 2 & 53 & 25 & 0 & 20 & $67.9 \%$ \\
\hline HPV 16-18-45 & 3 & 59 & 19 & 0 & 20 & $75.6 \%$ \\
\hline HPV 16-18-45-31 & 4 & 60 & 18 & 0 & 20 & $76.9 \%$ \\
\hline HPV 16-18-45-31-33 & 5 & 60 & 18 & 0 & 20 & $76.9 \%$ \\
\hline
\end{tabular}

${ }^{\mathrm{a} O n e}$ case with unknown HPV-type, thereby giving total positives 60 (TP60) instead of 61 (TP61). ${ }^{\mathrm{b}}$ Specificity was overall $100 \%$ because we included only cases with adenocarcinoma. 
Table III. Number of TP, FN, TN detected in HPV positives (by any method) in cervical adenocarcinoma using PreTect HPVProofer.

\begin{tabular}{|c|c|c|c|c|c|c|}
\hline HPV type in cocktail & \# Types & \# TP & \# FN & \# FPa & \# TN & Sensitivity \\
\hline 0 & 0 & 0 & 78 & 0 & 20 & $0.0 \%$ \\
\hline RNA16 & 1 & 32 & 46 & 0 & 20 & $41.0 \%$ \\
\hline RNA $16-18$ & 2 & 53 & 25 & 0 & 20 & $67.9 \%$ \\
\hline RNA $16-18-45$ & 3 & 63 & 15 & 0 & 20 & $80.8 \%$ \\
\hline RNA 16-18-45-31 & 4 & 63 & 15 & 0 & 20 & $80.8 \%$ \\
\hline RNA 16-18-45-31-33 & 5 & 63 & 15 & 0 & 20 & $80.8 \%$ \\
\hline
\end{tabular}

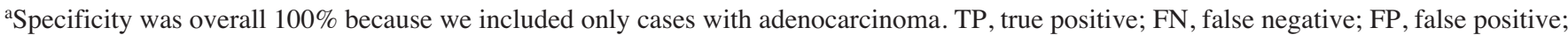
$\mathrm{TN}$, true negative.

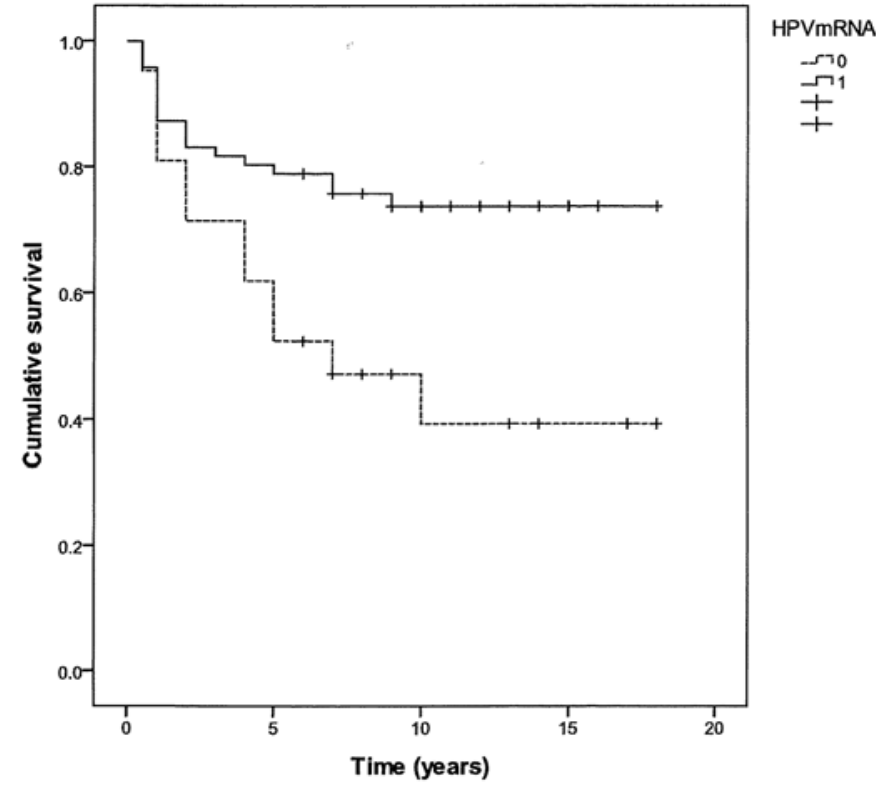

Figure 3. Unadjusted difference between HPV mRNA-negative and -positive patients. Kaplan and Meier curves of Cum Survival related to HPV E6/E7 mRNA expression detected by NASBA. HR-HPV E6/E7 mRNA negative cases $(n=35)$ had worse Cum Survival than those with detectable HR-HPV E6/E7 mRNA ( $n=63)$, but the difference was not statistically significant.

Overall agreement between the methods was seen in 82 of the 98 cases $(84 \%)$. An interesting finding was that mRNA for double types $16 / 18$ and $16 / 31$ was found in two cases where the equivalent type-specific DNA was detected only for HPV 16 in the 16/31 case, but was completely negative for DNA in the $16 / 18$ case by PCR.

In eight cases the E6/E7 mRNA assay and DNA analysis revealed different HPV types. Type mismatches are listed in Table I.

Performance of HPV DNA and HPV mRNA tests in regard to the mix of types in the test cocktail. Tables II and III show the change in sensitivity for detecting HPV positives after adding more HPV types and subjecting the sample to mRNA detection by NASBA and by HPV DNA assays. It is more meaningful to evaluate the performance of different HPV tests and typing in HPV positive cases alone because an HPV test cannot achieve a positivity rate of $100 \%$. Therefore, the coverage for the HPV types included in the E6/E7 mRNA assay has been calculated for HPV-positive cases by both methods.

The prognostic value of HPV analysis of cervical adenocarcinomas. Mean age of the HR-HPV negative group was 62 years, compared with 49 years for the HR-HPV positive patients. The observed age-adjusted hazard ratio for death as the event of interest, between the HR-HPV negative and HR-HPV positive patients was $1.77[(0.80 ; 3.90), \mathrm{P}=0.160]$. The unadjusted difference between HR-HPV negative and HR-HPV positive patients is presented in Fig. 3.

\section{Discussion}

The material for our study included 98 paraffin-embedded tissue samples of primary cervical adenocarcinomas, which were used to compare HPV detection by mRNA and DNAbased methods. We wanted to know whether detection of fulllength mRNA in the E6/E7 region of HR-HPV types provides a more sensitive method for detection of adenocarcinoma of the cervix due to transforming HPV infection than does DNA testing of paraffin-embedded tissue material.

We used PreTect HPV-Proofer, to detect full-length mRNA from HPV types 16, 18, 31, 33, and 45. To our knowledge, this study is the first to report on the usefulness of the NASBAbased PreTect HPV-Proofer assay in paraffin-embedded tissue samples of primary cervical adenocarcinomas. HR-HPV E6/E7 mRNA was detected in 63 of 98 (64\%) samples.

Eight cases $(8 \%)$ revealed different HPV types when using mRNA vs. DNA based assays. Kraus et al described the differences in HPV status between the results from NASBAanalysis vs. type specific PCR and found discordance in only 4 cases out of 202 samples (2\%) of squamous cervical carcinomas (21). In our study, all eight cases were obtained using SSCP rather than type-specific PCR, which may be one reason why discordance was higher in this study than in the study of Kraus et al (21). In four of these cases RLB was analyzed, which detected the same HPV types found using the PreTect HPV-Proofer. Our study found agreement between the mRNA and DNA methodology for HPV type (any type) in $77 \%$ of cases. Detection of HPV mRNA thus 
seems to be at least as feasible as HPV DNA detection in formalin fixed paraffin-embedded tissue. When examining fresh-frozen tumor tissues, prevalence of HR-HPV may be higher because alterations in the DNA sequence may be caused by formalin fixation and storage in paraffin (22-24).

We found recovery of mRNA for amplification to be highly dependent on the extraction procedure (results not shown); performance of downstream assays increases with decreasing amplicon length. Amplification of the U1A fragment, which is $\sim 100$ bp longer than the HPV amplicons in the PreTect HPV-Proofer assay, was unsuccessful.

Previous studies, using the sensitive PCR technique for detection of HPV DNA on formalin-fixed, paraffin-embedded biopsy specimens of cervical adenocarcinomas, reported HPV positivity at rates ranging from 32 to $85 \%(25,26)$.

Differences in sensitivity may be due to use of different DNA/RNA extraction methods, primers, and consensus and/or HPV type-specific primers, as well as to differences in preparation, fixation, and processing of the sample tissue. However, the main reason for these differences may be lack of control for the presence of cancer tissue in all sections collected. In this study, it was not possible to include histological evaluation of tissue samples both before and after the tissue was used for RNA/DNA extraction. Another factor which may reduce efficiency of HPV detection is loss of portions of the viral genome during integration. Integration of HPV DNA may result in deletion of the viral genome containing the sequences targeted by the PCR reaction. The absence of an episomal HPV genome in the majority of glandular tumors (27), as opposed to squamous tumors, may result in significant underestimation of HPV DNA and cervical adenocarcinomas (28). Although little is known about the possible transient nature of E6/E7 expression, the E6 and E7 oncoproteins play significant roles in malignant transformation, and are consistently expressed in malignant tissue. All 18 samples that were HPV-negative by all methods were reviewed by an experienced independent pathologist for cervical origin, as well as for grading and staging. Further analysis of relevant cases for histological genesis was carried out on a total of 13 samples using immunhistochemistry for vimentin and CEA. In the five remaining cases, there was insufficient material to carry out further investigations. Positive staining for vimentin and negative staining for CEA would indicate an endometrial origin for the cancer. None of the samples showed this pattern. Cervical origin would be clearly indicated by positive staining for CEA and negative staining for vimentin; this finding was noted in only two samples (29-31).

Interestingly, both assays showed a coverage for HPV of $\sim 70 \%$ when targeting HPV 16 and 18 alone. Overall, if we focus on the 77 HPV-positive cases (DNA and mRNA), the coverage for HPV types $16,18,31$, and 45 is $99 \%$. An unknown HPV type detected with DNA typing showed mRNA type 16 with the PreTect HPV-Proofer and was also confirmed to be DNA type 16 with RLB hybridization. HPV DNA type 52 detected by LA is the one and only case that stood in the way of a $100 \%$-detection rate for these four HR HPV types. The Linear Array assay detects HPV type 52 in the same position as HPV 33, 35, and 58. An additional band at specific positions for the latter 3 types is required to score for these types, which makes HPV 52 especially vulnerable to false positivity by LA assay.

The 28 negative HPV cases which were re-extracted in a third round before LA analysis could not be re-analyzed for mRNA with the PreTect HPV-Proofer due to insufficient sample material. Consequently, the positive LA results could not be compared in the statistical calculations.

We conservatively estimate that $35-52 \%$ of all cases of adenocarcinoma in our Swedish (6) population is attributable to HPV 16 and 18. The first-generation of HPV vaccines targeting these two most common types is currently on the market and vaccination should be able to prevent at least one-third of cervical adenocarcinomas and their precursor lesions in our population. Despite the worrisome increase in the incidence of adenocarcinoma in recent decades, there is cause for optimism. Through a combination of continuous public education about HPV transmission, improved detection of precursor lesions to cervical carcinoma by incorporating HPV testing into screening programs, and through a continuing vaccination program for HPV 16 and 18, cervical carcinoma may become one of the most preventable major forms of cancer on a global scale.

Thus, detection of mRNA transcripts of HPV genes known to be involved in oncogenesis may be more useful and sensitive than the exclusive use of HPV DNA tests to detect active and potentially persistent infection (32). Since HPVProofer always detects full-length E6/E7 mRNA, a positive result should correlate very well with integrated HPV, loss of HPV replication, and stabilized E6/E7 full-length mRNA expression. Stabilized E6/E7 full-length mRNA caused by integration of HPV correlates very well with high, stable expression of full-length E6 proteins, which results in a response from both p16 and p14 (33).

It has been suggested that p16 transcription may be directly induced by transcription factor E2F, released from $\mathrm{pRb}$ after binding to the HR-HPV E7 protein (34). In our previous study of cervical adenocarcinoma, we showed that levels of the tumor suppressor protein p16INK4a are higher in poorly differentiated tumors and in HPV-positive tumors than in HPV-negative tumors (16). No correlation was found between clinical outcome, stage, and histological grade in this study of patients with detectable full-length E6/E7 mRNA.

Our data indicate that mRNA HPV testing is at least as sensitive as an HPV DNA testing for identifying women with cervical adenocarcinoma. Since most adenocarcinomas are HPV-positive, it is possible that mRNA testing will have a stronger impact on prevention of adenocarcinoma than cytological screening, especially in young females. Thus, $\mathrm{E} 6 / \mathrm{E} 7$ oncogene expression analysis of precursor lesions (i.e. adenocarcinoma in situ and glandular dysplasia) will be the next step to verify the potential of E6/E7 expression as a molecular marker for early detection and progression to invasive disease. In contrast to cytology, detection of E6/E7 HPV mRNA is an objective molecular marker, and may allow diagnosis of cervical adenocarcinoma at an earlier stage in the natural history of the disease. The ability to detect almost all HPV-related adenocarcinomas, including the limited HPV types covered by the PreTect HPV-Proofer assay, is a new discovery that underlines the potential of this test for adenocarcinoma screening. 
Consequently, we are planning to conduct both retrospective studies using archival Pap smears and prospective randomized studies with routinely collected Pap smears.

\section{Acknowledgements}

This study was supported by the Swedish Cancer Foundation (070623, CAN 2007/1044), KI Cancer Strategic Grants (5888/05-722), Swedish Research Council (521-2008-2899), Medical Research Council, and Cancer Society in Stockholm, Stockholm County Council, and Swedish Labour Market Insurance. We wish to thank Carmen Flores-Staino for technical assistance.

\section{References}

1. IARC (International Agency for Research on Cancer) monographs on the evaluation of carcinogenic risks to humans. In: Human Papillomaviruses. Vol. 90, Lyon, France, 2007.

2. Socialstyrelsen, Epidemiologiskt centrum Cancer incidence in Sweden, 2008.

3. Smith HO, Tiffany MF, Qualls CR and Key CR: The rising incidence of adenocarcinoma relative to squamous cell carcinoma of the uterine cervix in the United States - a 24-year populationbased study. Gynecol Oncol 78: 97-105, 2000

4. Bray F, Carstensen B, Møller H, Zappa M, Zakelj MP, Lawrence $\mathrm{G}$, et al: Incidence trends of adenocarcinoma of the cervix in 13 European countries. Cancer Epidemiol Biomarkers Prev 14: 2191-2199, 2005.

5. International Collaboration of Epidemiological Studies of Cervical Cancer: Comparison of risk factors for invasive squamous cell carcinoma and adenocarcinoma of the cervix: Collaborative reanalysis of individual data on 8,097 women with squamous cell carcinoma and 1,374 women with adenocarcinoma from 12 epidemiological studies. Int J Cancer 120: 885-891, 2006

6. Andersson S, Rylander E, Larson B, Sigurdardottir S, Backlund I, Sällström J, et al: Types of human papillomavirus revealed in cervical adenocarcinomas after DNA sequencing. Oncol Rep 10: $175-179,2003$

7. Meijer CJ, Snijders PJ and van den Brule AJ: Screening for cervical cancer: should we test for infection with high-risk HPV? CMAJ 163: 535-538, 2000.

8. Josefsson AM, Magnusson PK, Ylitalo N, Sorensen P, Qwarforth-Tubbin P, Andersen PK, et al: Viral load of human papilloma virus 16 as a determinant for development of cervical carcinoma in situ: a nested case-control study. Lancet 355: 2189-2193, 2000.

9. Smith JS, Lindsay L, Hoots B, Keys J, Franceschi S, Winer R, et al: Human papillomavirus type distribution in invasive cervical cancer and high-grade cervical lesions: a meta-analysis update. Int J Cancer 121: 621-632, 2007.

10. Munger K, Baldwin A, Edwards KM, Hayakawa H, Nguyen CL, Owens M, et al: Mechanisms of human papillomavirus-induced oncogenesis. J Virol 78: 11451-11460, 2004.

11. Schwarz E, Freese UK, Gissmann L, Mayer W, Roggenbuck B, Stremlau A, et al: Structure and transcription of human papillomavirus sequences in cervical carcinoma cells. Nature 314 111-114, 1985

12. zur Hausen H: Papillomaviruses and cancer: from basic studies to clinical application. Nat Rev Cancer 2: 342-350, 2002.

13. Ho GY, Bierman R, Beardsley L, Chang CJ and Burk RD: Natural history of cervicovaginal papillomavirus infection in young women. N Engl J Med 338: 423-428, 1998.

14. Jacobs MV, Walboomers JM, Snijders PJ, Voorhorst FJ Verheijen RH, Fransen-Daalmeijer N, et al: Distribution of 37 mucosotropic HPV types in women with cytologically normal cervical smears: the age-related patterns for highrisk and lowrisk types. Int J Cancer 87: 221-227, 2000.

15. Sotlar K, Selinka HC, Menton M, Kandolf R and Bültmann B: Detection of human papillomavirus type 16 E6/E7 oncogene transcripts in dysplastic and nondysplastic cervical scrapes by nested RT-PCR. Gynecol Oncol 69: 114-121, 1998.
16. Muller S, Flores-Staino C, Skyldberg B, Hellström AC, Johansson B, Hagmar B, et al: Expression of p16INK4a and MIB-1 in relation to histopathology and HPV types in cervical adenocarcinoma. Int J Oncol 32: 333-340, 2008.

17. Andersson S, Larson B, Hjerpe A, Silfversward C, Sallstrom J, Wilander E, et al: Adenocarcinoma of the uterine cervix: the presence of human papillomavirus and the method of detection. Acta Obstet Gynecol Scand 82: 960-965, 2003.

18. Zehbe I, Evander M, Edlund K, Rylander E, Wadell G and Wilander E: Non-radioisotopic detection and typing of human papillomavirus (HPV) by use of polymerase chain reaction and single strand conformation polymorphism (PCR-SSCP). Diagn Mol Pathol 5: 206-213, 1996.

19. van den Brule AJ, Pol R, Fransen-Daalmeijer N, Schouls LM, Meijer CJ and Snijders PJ: GP5 ${ }^{+} / 6^{+}$PCR followed by reverse line blot analysis enables rapid and high-throughput identification of human papillomavirus genotypes J. Clin Microbiol 40: 779-787, 2002.

20. Muñoz N, Bosch FX, de Sanjosé S, Herrero R, Castellsagué X, Shah KV, et al: International Agency for Research on Cancer Multicenter Cervical Cancer Study Group. Epidemiologic classification of human papillomavirus types associated with cervical cancer. N Engl J Med 348: 518-527, 2003.

21. Kraus I, Molden T, Holm R, Lie AK, Karlsen F, Kristensen GB, et al: Presence of E6 and E7 mRNA from human papillomavirus types $16,18,31,33$ and 45 in the majority of cervical carcinomas. J Clin Microbiol 44: 1310-1317, 2006.

22. Williams C, Ponten F, Moberg C, Soderkvist P, Uhlen M, Ponten $\mathrm{J}$, et al: A high frequency of sequence alterations is due to formalin fixation of archival specimens. Am J Pathol 155: 1467-1471, 1999.

23. Tang E: Path to effective recovering of DNA from formalinfixed biological samples in natural history collections: workshop summary. Ed. National Research Council. National Academy Press, Washington, DC, 2006.

24. Karlsen F, Kalantari M, Chitemerere M, Johansson B and Hagmar B: Modifications of human and viral deoxyribonucleic acid by formaldehyde fixation. Lab Invest 71: 604-611, 1994

25. Clifford GM, Smith JS, Plummer N, Munoz N and Franceschi S: Human papillomavirus types in invasive cervical cancer worldwide: a meta-analysis. Br J Cancer 88: 63-73, 2003.

26. Duggan MA, McGregor, Benoit JL, Inoue M and Stuart GCE: The human papillomavirus status of invasive cervical adenocarcinoma: A clinicopathological and outcome analysis. Hum Pathol 26: 319-325, 1995

27. Park JS, Hwang ES, Park SN, Ahn HK, Um SJ, Kim CJ, et al: Physical status and expression of HPV genes in cervical cancers. Gynecol Oncol 65: 121-129, 1997.

28. Chung JY, Braunschweig T, Williams R, Guerrero N, Hoffmann KM, Kwon M, et al: Factors in tissue handling and processing that impact RNA obtained from formalin-fixed, paraffin-embedded tissue. J Histochem Cytochem 56: 1033-1042, 2008.

29. McCluggage WG, Sumathi VP, McBride HA and Patterson A: A panel of immunohistochemical stains, including carcinoembryonic antigen, vimentin, and estrogen receptor, aids the distinction between primary endometrial and endocervical adenocarcinomas. Int J Gynecol Pathol 21: 11-15, 2002.

30. Castrillon DH, Lee KR and Nucci MR: Distinction between endometrial and endocervical adenocarcinoma: an immunohistochemical study. Int J Gynecol Pathol 21: 4-10, 2002.

31. Zielinski GD, Snijders PJ, Rozendaal L, Daalmeijer NF, Risse EK, Voorhorst FJ, et al: The presence of high-risk HPV combined with specific p53 and p16INK4a expression patterns points to high-risk HPV as the main causative agent for adenocarcinoma in situ and adenocarcinoma of the cervix. J Pathol 201: 535-543, 2003.

32. Ylitalo N, Sorensen P, Josefsson AM, Magnusson PK, Andersen PK, Ponten J, et al: Consistent high viral load of human papillomavirus 16 and risk of cervical carcinoma in situ: a nested case-control study. Lancet 355: 2194-2198, 2000.

33. Wang JL, Zheng BY, Li XD, Angström T, Lindström MS and Wallin KL: Predictive significance of the alterations of p16INK4A, p14ARF, p53, and proliferating cell nuclear antigen expression in the progression of cervical cancer. Clin Cancer Res 10: 2407-2414, 2004.

34. Khleif SN, DeGregori J, Yee CL, Otterson GA, Kaye FJ, Nevins JR, et al: Inhibition of cyclin D-CDK4/CDK6 activity is associated with an E2F-mediated induction of cyclin kinase inhibitor activity. Proc Natl Acad Sci USA 93: 4350-4354, 1996. 